\title{
Lihaksikkaalla kalkkunallako lihasongelmia?
}

\author{
Maria Ylä-Ajos, Laura Hänninen ja Anna Valros \\ HY, kliinisen tuotantoeläinlääketieteen laitos, PL 57, 00014 HELSINGIN YLIOPISTO, \\ etunimi.sukunimi@helsinki.fi
}

Kalkkunoiden hyvinvointiongelmat ovat ajankohtaisia sekä kotimaassa että maailmalla. Kalkkunan lihantuotanto-ominaisuuksien jalostuksella on onnistuttu parantamaan erinomaisesti eläinten rehuhyötysuhdetta, kasvunopeutta ja lihasmassaa verrattuna vastaavanikäiseen vähemmän jalostettuun lajitoveriin. Jalostuksessa on kuitenkin saatettu haluttujen ominaisuuksien ohella valita geenejä, jotka aiheuttavat häiriöitä kalkkunoiden lihasten toimintaan ja niiden rakenteeseen. Nopeasta kasvusta saattaa aiheutua eläimille hyvinvointiongelmia kuten jalkojen heikkoutta, alentunutta kävelykykyä ja lihassairauksia. HY eläinlääketieteellisessä tiedekunnassa tehty kalkkunoiden hyvinvointia teuraskuljetuksen aikana mittaava tutkimus paljasti lintujen veren lihasentsyymipitoisuuksien (kreatiinikinaasi, CK) olevan huomattavan korkeita. Kalkkunoiden verenkierron kohonnut CK pitoisuus on todettu muissakin tutkimuksissa, ja sen oletetaan olevan merkki voimakkaasti kasvavan linnun reisi- ja/tai rintalihasten solutuhoista. Ruokinnan rajoittamisella pystytään alentamaan jalostettujen kalkkunoiden plasman CK pitoisuutta, mutta pitoisuus pysyy siitä huolimatta korkeampana kuin perinteisten, jalostamattomien kalkkunoiden veressä. Siitä, aiheutuuko linnuille lihasten solutuhojen johdosta kipua, ei ole tutkittua tietoa.

Tämän Maa- ja metsätalousministeriön rahoittaman tutkimuksen tavoitteena on tutkia teuraaksi kasvatettavien kalkkunoiden nopeaan kasvuun liittyviä lihasentsyymimuutoksia ja näihin mahdollisesti liittyviä käyttäytymismuutoksia. Hypoteesimme on, että kalkkunoilla esiintyy yleisesti kroonista reisija/tai rintalihasten solutuhoista aiheutuvaa kipua. Solutuhoja indikoi verenkierron kohonnut CK. Oletuksena on, että kalkkunoiden tuntema kipu voidaan osoittaa seuraamalla kipulääkityksen vaikutuksia kalkkunoiden käyttäytymiseen, erityisesti niiden liikuntahalukkuuteen.

Esikokeessa 15 kalkkunaa jaettiin kahteen yhtäläiseen ryhmään veren $\mathrm{CK}$ pitoisuuden perusteella. Toiselle ryhmälle annosteltiin kerran päivässä kolmen päivän ajan kipulääkettä ja toiselle ryhmälle vastaavasti plaseboa. Kalkkunoiden käyttäytymistä kotikarsinassaan, kävelykykyä ja liikuntahalukkuutta testiradalla seurattiin ennen kipulääkitystä ja sen aikana. Liikuntahalukkuustestissä mitattiin eläinten kävelynopeutta, kiihtyvyyttä, ketteryyttä ja käyttäytymistä. Eläinten motivaatiota toimia testiradalla kasvatettiin ruokapalkinnolla ja testiä edeltävällä lyhyellä paastolla. Liikuntatestien jälkeen eläimet lopetettiin ja niiden nivelien ja jalkapohjien kunto tarkastettiin. Rinta- ja reisilihaksista otetuille näytteille tehdään histologinen tutkimus. Varsinainen tutkimus 40 kalkkunalla käynnistyy keväällä 2010. Mikäli veren kohonneen CK pitoisuuden todetaan olevan merkki kalkkunoiden kokemasta kroonisesta kivusta, on kalkkunoiden jalostus- ja ruokintaohjelmat sekä teuraskuljetusten järjestäminen uudelleen arvioitava.

Asiasanat: kalkkuna, hyvinvointi, jalostus, lihasongelmat, kreatiinikinaasi 


\section{Johdanto}

Kalkkunoiden tuotanto-ominaisuuksien jalostuksessa on onnistuttu hyvin. Lihantuotantoa varten jalostetut linnut kasvavat erittäin nopeasti, hyvällä rehuhyötysuhteella ja niiden lihasmassa on vastaavanikäistä vähemmän jalostettua lajitoveria huomattavasti suurempi. Jalostuksessa on kuitenkin saatettu haluttujen ominaisuuksien ohella valita geenejä, jotka aiheuttavat häiriöitä kalkkunoiden lihasten toimintaan ja niiden rakenteeseen (Mills, Mitchell, \& Mahon, 1998). Nopeasta kasvusta saattaa aiheutua eläimille hyvinvointiongelmia, kuten jalkojen heikkoutta, alentunutta kävelykykyä ja lihassairauksia. Suomessa (Wichman ym., artikkeli painossa) ja maailmalla (Hocking, Mitchell, Bernard, \& Sandercock, 1998; Mills, Mitchell, \& Mahon, 1998) on todettu teurasikäisten kalkkunoiden veren kreatiinikinaasi (CK) pitoisuuden olevan huomattavan korkea. CK on lihaksen sisällä toimiva entsyymi, ja sen pitoisuuden nousu verenkierrossa kertoo muutoksista solukalvon läpäisevyydessä. Veren kohonneen $\mathrm{CK}$ pitoisuuden oletetaankin olevan merkki voimakkaasti kasvavan linnun reisi- ja/tai rintalihasten solutuhoista (MacRae, Mahon, Gilpin, Sandercock, \& Mitchell, 2006; Mills, Mitchell, \& Mahon, 1998; Wilson, Nieberg, Buhr, Kelly, \& Shultz, 1990). Nuorilla eläimillä on epänormaaleja lihassoluja vain vähän, mutta lihasvaurioitten määrä kasvaa iän myötä (Mills, Mitchell, \& Mahon, 1998). Mills työryhmineen (1998) havaitsi jalostetuilla roduilla soluvaurioitten määrän kasvavan huomattavasti enemmän kuin jalostamattomilla kalkkunaroduilla ja veren CK pitoisuuden kasvun olevan jalostetuilla eläimillä iän myötä eksponentiaalista. Jalostettujen kalkkunoiden plasman CK pitoisuutta pystytään alentamaan ruokinnan rajoittamisella, mutta pitoisuus pysyy siitä huolimatta korkeampana kuin perinteisten, jalostamattomien kalkkunoiden veressä (Hocking, Mitchell, Bernard, \& Sandercock, 1998). Siitä, aiheutuuko linnuille lihasten solutuhojen vuoksi kipua, ei ole tutkittua tietoa.

Tämän tutkimuksen tavoitteena on tutkia kalkkunoiden hyvinvointia kasvatuksen aikana. Hypoteesimme on, että kalkkunoiden verenkierron epänormaalin korkea kreatiinikinaasipitoisuus on merkki lintujen kroonisista lihaskivuista. Nämä lihaskivut johtuvat reisi- ja/tai rintalihasten soluvaurioista.

\section{Aineisto ja menetelmät}

Eläimet ja pitopaikan olosuhteet

Pilottikokeeseen hankittiin viisitoista kalkkunakukkoa (Nicholas 300 x T8) 12 viikon iässä kalkkunakasvattamosta koe-eläinyksikköön ja merkittiin rengastamalla. Eläimiä pidettiin kiinteäpohjaisessa kutterin purulla kuivitetussa karsinassa. Pitopaikan lämpötila oli välillä $20-22{ }^{\circ} \mathrm{C}$ ja ilmankosteus 51-62\%. Valot olivat päällä kello 7.00 ja 23.00 välisen ajan, valaistuksen intensiteetin vaihdellessa välillä 0,5-10 lux. Eläimille pidettiin jatkuvasti tarjolla vettä sekä rehuseosta, joka koostui kaupallisesta kalkkunanrehusta (Suomen rehu, Iso punaheltta 3), vehnästä ja kaurasta suhteessa 30:58:12. Rehuseoksen koostumus vastasi kasvatustilalla käytössä ollutta seosta. Lisäksi eläimiä totutettiin kotikarsinassaan syömään erillisestä astiasta herkkurehua (kuorittu auringonkukansiemen + kypsä kinkkusuikale). Eläinten painonkehitystä seurattiin viikoittain (Sartorius F150S-D2, Göttingen, Germany).

\section{Kipulääkityksen vaikutus kalkkunoitten liikuntahalukkuuteen}

Neljäntoista viikon iässä kalkkunoita alettiin harjoittaa suoralla yhden $\mathrm{n} .10 \mathrm{~cm}$ korkean esteen sisältävällä liikuntahalukkuustestiradalla (Bokkers \& Koene, 2002). Rata mitoitettiin kalkkunoille sopivaksi (pituus 7,6 m, leveys 1,0 m, seinämän korkeus $1,2 \mathrm{~m}$ ) ja se sisälsi yhden $15 \mathrm{~cm}$ korkean esteen. Kalkkunoita totutettiin rataan aluksi kaksi kertaa 2-3 eläimen ryhmissä eristysstressin vähentämiseksi. Totutusta jatkettiin viemällä eläimet kahdesti yksin radalle ennen varsinaisten testausten alkamista. Eläinten annettiin ensin liikkua muutamia minuutteja vapaasti radalla. Lopuksi ne ohjattiin hellävaraisesti radan lopussa odottavan ruokapalkinnon luokse elleivät ne itse sinne menneet.

Kalkkunoiden veren $\mathrm{CK}$ pitoisuus mitattiin 14 viikon iässä ja eläimet jaettiin sen mukaan kahteen yhtäläiseen ryhmään. Viidentoista viikon iässä ensimmäiselle ryhmälle annettiin kerran päivässä kolmen päivän ajan kipulääkitystä suun kautta aloitusannoksella $0,2 \mathrm{mg} / \mathrm{kg}$ ja jatkoannostelulla $0.1 \mathrm{mg} / \mathrm{kg}$ (meloksikaami, $1,5 \mathrm{mg} / \mathrm{ml}$, Metacam, Boehringer Ingelheim). Toiselle ryhmälle annettiin fysiologista suolaliuosta plasebona. Edellä esitetty liikuntahalukkuustestaus 
toistettiin molemmille ryhmille ennen ja jälkeen käsittelyn ja kalkkunoiden suoritus radalla nauhoitettiin. Suoritukselle annettiin maksimiajaksi 3 min, jonka jälkeen eläin ajettiin hellävaraisesti radan lopussa odottavan ruokapalkinnon luokse, mikäli se ei itse sinne mennyt. Kävelymotivaation kohottamiseksi testikertoja edelsi 2-4 h paasto.

Lintuja kuvattiin kotikarsinassaan vuorokauden ajan ennen kipulääkitystä sekä kipulääkitysjakson aikana. Karsina-alueen kattavat kolme värikameraa (TS 6030 IR) kiinnitettiin karsinarakenteisiin. Kamerat oli yhdistetty AVC-717 MPEG4 digitaalitallentimeen. Tallenteista tehtiin käyttäytymishavaintoja käyttäen apuna Observer 5.0 ohjelmistoa (Noldus Information Technology B.V., Wageningen, Hollanti). Kuvausvuorokauden aikana linnuista havainnoitiin mm. miten suuren osan ajasta ne olivat seisaallaan, liikkeessä, makuulla tai istumassa. Muu käyttäytyminen, kuten sukiminen tai siipien oikominen, kirjattiin tapahtumana ja niiden frekvenssit rekisteröitiin.

\section{Veren CK pitoisuus}

Kalkkunoista otettiin verinäytteet kreatiinikinaasin (CK) aktiivisuuden määritystä varten siipisuonesta. Näytettä otettaessa kalkkunan pää ja suurin osa kehoa peitettiin kevyellä puuvillapeitteellä ja lintua pidettiin kyljellään. Verinäyte otettiin 14 viikon ikäisiltä $3 \mathrm{ml}$ EDTA -vakuumiputkeen ja 16 viikon ikäisiltä $3 \mathrm{ml}$ plasma -vakuumiputkeen. Veriplasma erotettiin sentrifugoimalla verta 10 minuuttia $(2100$ g) ja CK aktiivisuus määritettiin automaattisella seerumin kemikaalien analyysilaitteella (Konelab 30i Clinical Chemistry Analyzer, Thermo Fisher Scientific, Vantaa, Finland) standardoidulla IFCC menetelmällä.

Tutkimuksella on eläinkoelautakunnan hyväksyntä.

\section{Tulokset ja tutkimuksen merkitys}

Huolimatta siitä että kalkkunantuotanto on ollut muutamia vuosia hienoisessa laskussa, vuonna 2008 Suomessa teurastettiin 1,16 miljoonaa kalkkunaa, joiden ruhopaino oli yhteensä 9,97 milj $\mathrm{kg}$ (MMMTike, teurastamotilasto). Teurastusmäärien laskiessa teurastusikä ja teuraspaino ovat nousseet. Jalostettujen kalkkunoiden veren $\mathrm{CK}$ pitoisuuden on havaittu nousevan 12 viikon iästä alkaen nopeammin ja olevan 18 viikon iässä yli kaksinkertainen jalostamattomiin kalkkunoihin verrattuna (Hocking, Mitchell, Bernard, \& Sandercock, 1998). Tämän tutkimuksen tarkoituksena on selvittää kalkkunoiden veren epänormaalin korkean CK pitoisuuden mahdollista yhteyttä lintujen kroonisiin lihaskipuihin. Tutkimuksen pilottivaiheen kokeellinen osuus on päättynyt. Tässä esitellään sen tuloksia siltä osin kuin ne ovat valmiina.

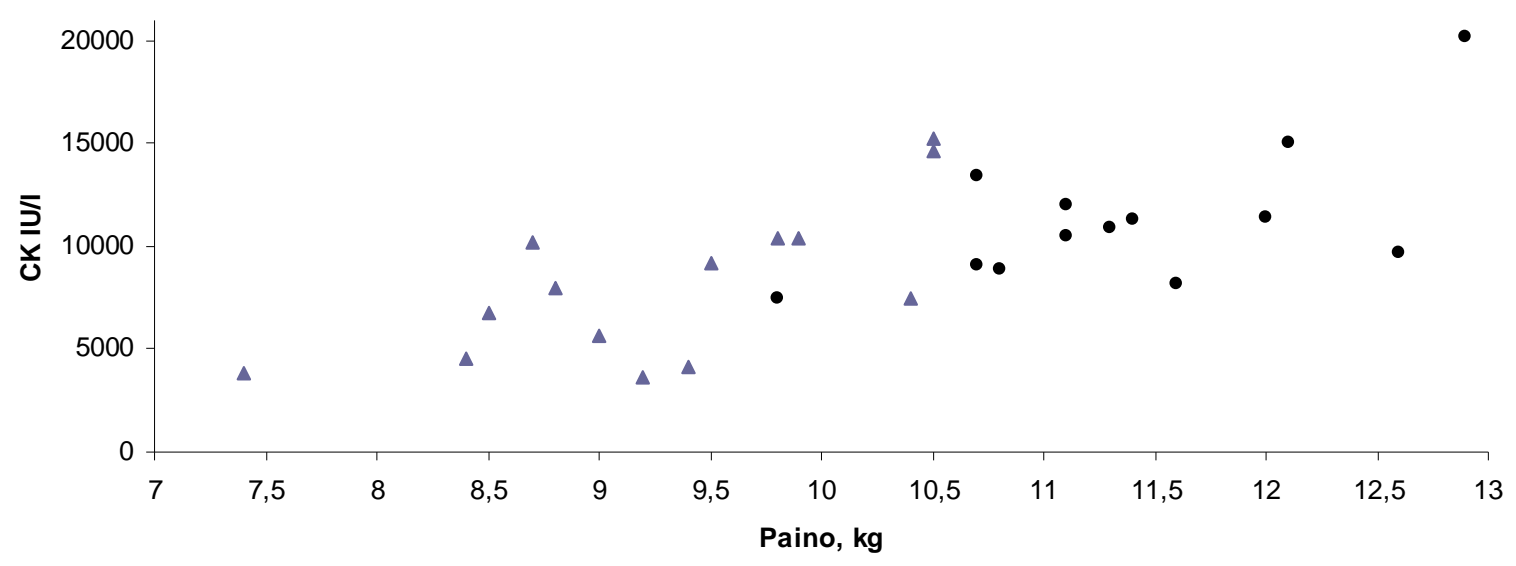

Kuva 1: Veren CK pitoisuus suhteessa elopainoon 14 viikon $(\boldsymbol{\Delta})$ ja 16 viikon $(\bullet)$ ikäisillä kalkkunakukoilla.

Kalkkunoiden veren CK pitoisuus kasvoi elopainon kasvaessa (Kuva 1). Linnut painoivat 14 viikkoisina 9,3 $\pm 0,9 \mathrm{~kg}$ ja veren $\mathrm{CK}$ pitoisuus oli $8,1 \pm 3,8 \mathrm{IU} / \mathrm{l}$. Vastaavat arvot 16 viikon iässä olivat $11,4 \pm 0,8 \mathrm{~kg}$ ja $11,4 \pm 3,4$ IU/l. Lineaarinen korrelaatio painon ja CK pitoisuuden välillä oli 14 viikon 
iässä 0,69 (p=0,003) ja 16 viikon iässä $0,61(\mathrm{p}=0,013)$. Kohonneen CK:n oletetaan olevan merkki voimakkaasti kasvavan linnun reisi- ja/tai rintalihasten solutuhoista (MacRae, Mahon, Gilpin, Sandercock, \& Mitchell, 2006; Wilson, Nieberg, Buhr, Kelly, \& Shultz, 1990).

Kalkkunoiden kävelykykyä ja liikuntahalukkuutta testattiin ennen kipulääkitystä ja kipulääkityksen aikana tarkoitusta varten rakennetulla liikuntahalukkuustestiradalla. Testi mittasi kalkkunoiden kävelynopeutta, kiihtyvyyttä ja sitä miten nopeasti ne selviävät radasta. Kipulääkityksen on havaittu pidentävän seitsenviikkoisten kalkkunoiden jalkojensa varassa viettämää aikaa verrattuna lääkitsemättömiin kalkkunoihin (Buchwalder \& Huber-Eicher, 2005). Lintujen mahdollisten lihaskipujen tutkimista vaikeuttaa se, että linnut pyrkivät luontaisesti olemaan näyttämättä kipuaan (Machin, 2005). Eläimellä voidaan olettaa olleen kipuja, mikäli kipulääkityksellä on vaikutusta eläimen käyttäytymiseen, kuten aktiivisuuteen ja liikuntahalukkuuteen (Buchwalder \& Huber-Eicher, 2005). Tämän kokeen tallenteiden analysointi on kesken, joten ei voida vielä päätellä, heijastaako veren kohonnut CK myös kalkkunoiden kokemaa lihasperäistä kipua.

Koska kalkkunoilla saattaa olla muitakin kuin lihaksista johtuvia kävelyvaikeuksia, niiden nivelten ja jalkapohjien kunto tarkastettiin lintujen lopetuksen yhteydessä. Rinta- ja reisilihaksista otettiin näytteet, joista kartoitetaan lihassolujen tila. Näytteiden analysointi on vielä kesken.

Lihantuotantoon jalostettujen kalkkunoiden veren CK pitoisuudet olivat epänormaalin korkeita. Mikäli tämän todetaan olevan merkki kalkkunoiden kokemasta kivusta, on kalkkunoiden jalostus- ja ruokintaohjelmat sekä teuraskuljetusten järjestäminen uudelleen arvioitava.

\section{Jatkosuunnitelmat}

Varsinainen koe suoritetaan keväällä 2010 neljälläkymmenellä kalkkunakukolla, jotka hankitaan 14 viikon iässä kalkkunakasvattamosta.

Mikäli kipulääkityksen havaitaan saavan aikaan vasteen lintujen käyttäytymisessä, suoritetaan jatkokoe uudella kalkkunaryhmällä. Näille eläimille tarjotaan mahdollisuus kivun itselääkintään syömällä valintansa mukaan joko normaalia rehua tai kipulääkepitoista rehua. Kalkkunoiden käyttäytymistä seurataan kuten edellä sekä mitataan eri rehujen kulutusmäärät punnitsemalla.

\section{Kirjallisuus}

Bokkers, E. A. M., \& Koene, P. (2002). Sex and type of feed effects on motivation and ability to walk for a food reward in fast growing broilers. Applied Animal Behaviour Science, 79(3), 247-261.

Buchwalder, T., \& Huber-Eicher, B. (2005). Effect of the analgesic butorphanol on activity behaviour in turkeys (Meleagris gallopavo). Research in veterinary science, 79(3), 239-244.

Hocking, P. M., Mitchell, M. A., Bernard, R., \& Sandercock, D. A. (1998). Interaction of age, strain, sex and food restriction on plasma creatine kinase activity in turkeys. British poultry science, $39(3), 360-364$.

Machin, K. L. (2005). Avian pain: Physiology and evaluation. COMPENDIUM ON CONTINUING EDUCATION FOR THE PRACTICING VETERINARIAN, 27(2), 98-108.

MacRae, V. E., Mahon, M., Gilpin, S., Sandercock, D. A., \& Mitchell, M. A. (2006). Skeletal muscle fibre growth and growth associated myopathy in the domestic chicken (Gallus domesticus). British poultry science, 47(3), 264-272.

Mills, L. J., Mitchell, M. A., \& Mahon, M. (1998). Incidence of skeletal muscle damage in selected and unselected strains of turkey. British poultry science, 39, S27-S28.

Wichman, A. et al. Effect of cage height during short-term restriction on the welfare and behaviour of turkeys. (Manuscript).

Wilson, B. W., Nieberg, P. S., Buhr, F. T., Kelly, B. J., \& Shultz, F. T. (1990). Turkey muscle growth and focal myopathy. Poultry science, 69(9), 1553-1562. 